\title{
Comparative Study of Throughput in MANET Routing Protocols with Variable Nodes using NS-2
}

\author{
Purushottam Kewat \\ Department of CS and IT Dr. C.V. Raman \\ University, Kargi Road Kota, Bilaspur Chhattisgarh, \\ India
}

\author{
Akhilesh Kumar Shrivas \\ Department of CS and IT Dr. C.V. Raman \\ University, Kargi Road Kota, Bilaspur Chhattisgarh, \\ India
}

\begin{abstract}
Mobile Ad-hoc Network (MANET) is a collecting of wireless moveable nodes dynamically forming a temporary mesh without the aid of any constituted store or centralized body. As in MANET, the network anatomy is changing and often changes, so routing protocols should be fashioned to athletics the obligation of the MANET. It is a determinant division in the action valuation of MANET to select suitable mobility model have been proposed for ad hoc wireless networks based on diametrical scenarios. In this theme, we speculated and equated the action of the routing protocols AODV, DSDV, DSR and OLSR with indicator to varying throughput.
\end{abstract}

\section{Keywords}

MANET, Ad hoc On-Demand Distance Vector (AODV), Destination Sequenced Distance Vector Routing (DSDV), Dynamic Source Routing (DSR), Optimized Link State Routing Protocol (OLSR)

\section{INTRODUCTION}

An Adhoc Network is a grouping of wireless nodes that can dynamically strain a mesh to include both structure wireless networks and infrastructure less ambulatory ad hoc networks (MANETs) [1]. MANET routing protocols can be characterized into two categories: proactive and reactive (ondemand) [2]. Proactive routing protocols conclude paths for all source-destination pairs in suggestion and stores in the routing table. In this type of rule, each convexity periodically exchanges the routing content by broadcasting. The protocols are also renowned as table-driven routing protocol. Destination Sequenced Distance Vector Routing (DSDV) and OLSR (Optimized Union Dos Routing) is a proactive routing rule. Unstable routing protocols distinguish a line when a covering of routing nonstarter occurs the prescript discovers a cyclical itinerary. Dynamic Source Routing (DSR) and Adhoc On-demand Distance Vector (AODV) routing prescript are the most common routing protocols [3].

\section{RELATED WORK}

There are various authors have worked in field of MANET routing protocols.Vahid Garousi [4] affected on a reasoning of web interchange in MANET based on the DSDV protocol. It is intensity on mobility and connection patterns of the nodes.

They observed that simulations rhythmic the action of DSDV routing rule system configuration changes in status of scene size, motorized nodes movement and wares of connections among nodes. Das, S.R. et al. [5] analyzed the show of contrary protocols similar DSDV, AODV and DSR routing protocols for MANET using NS-2 simulator. This transform observed that DSDV uses the proactive table-driven routing strategy. In superior mobility simulations AODV and DSR fulfill ameliorate than that of DSDV. Chao, C. M. et al. [6] have discussed the show supported on packet style fraction and normalized routing in cumbrance. Author observed that the simulations could be carried out in collection packet deed and show reasoning on location-based routing protocols. Zamam , R. U [7] have discussed the action of DSDV, AODV and DSR routing protocols for MANET using NS-2 representation software. They observed and over that the competing activated routing protocols, AODV and DSR screw shown that the outgo action than the remaining in position of special show matrices. Perkins, C. E. et al. [8] individual planned a new and an effectual DSDV rule for ad hoc networks. Eff-DSDV (own new protocol) solved the difficulty of foil in flyblown routes, and hence, it improved the show of rhythmical DSDV. They change advisable packet delivery ratio, end-end delay, dropped packets, routing elevated, route size as a performance metrics. The planned prescript has been implemented in the NCTU NS Simulator. Finally, they constituted that the performance of Eff-DSDV is exceed than to frequent dropping judge for DSR is rattling little than DSDV and AODV and indicated that it hit maximal efficiency. Rahman, A. et al. [9] inebriated mobility occurs due to visit join failures and the foil implicated in updating all the nodes with the new routing collection as in DSDV. Khan, K. U. et al. [10] unnatural and compared the execution of routing protocols by using NCTUns 4.0 meshwork simulator. They observed that action of routing protocols was evaluated by varying separate of nodes in multiples of 5 in the ad hoc mesh. The simulations experience for this rumination is set to 70 seconds and packet filler was firm to 1400 bytes. Arun Kumar B. R. et al. [11] unnatural and constitute their observations regarding the show comparison of the routing protocols for variable bit rate (VBR) in nomadic ad hoc networks (MANETs). They created simulations environment, using NS-2 simulator and analyzed that unstable protocols perform outmatch than proactive protocols. Gowrishanker, S. et al. [12] analyzed the performance of AODV and OLSR by using NS-2 simulator, the simulation quantify point for each scenario was 900 seconds and the mesh area was $800 \mathrm{~m}$ x 500 $\mathrm{m}$. In someone of a piece technique scenario, all nodes were initially set at the point of the simulation location. They found that the nodes begin vibratory after the 10 seconds of simulated measure using this tools. Setty, S. P. et al. [13] have worked on mortal compared performance of existing wireless routing protocol AODV in various nodes placement models equivalent Network, Random and Uniform. Vetrivelan, N. et al. [14] analyzed the execution using varied network size and simulation times. They evaluated two framework experiments for 10 and 25 nodes for representation instant up to 100 second. Mahmoud, A. E. et al. [15] have practical different MANET protocols equivalent AODV, DSDV and I-DSDV in NS-2 simulators and compared show in damage of packet throw ratio, end to end boat holdup and 
routing expense in varied surroundings, varying find of nodes, and delay example. Results launch that; I-DSDV reduced the find of dropped assemblage packets compared with DSDV. Jorg, D.O. [16] have analyzed the doings of MANET protocols on scheme anatomy changes resulting from command as profound loads, countertenor mobility environment, deep figure of interchange sources and larger company of nodes in the network. Broch, J. et al. [17] analyzed the execution and comparison of both proactive and reactive routing protocols. They have utilized Ns-2 simulation tool for fixed 50 nodes on variable pause clock time and diverse apparent movement designs pattern.

\section{SIMULATION TOOL}

Network Simulator-2 (NS-2) is an afford inspiration, separate circumstance network simulator. It is victimized for the technique of fabric protocols with assorted scheme topologies. It is surefooted of simulating wired as well as wireless networks. NS-2 was stacked in $\mathrm{C}++$ and provides the model port through $\mathrm{OTcl}$, an object-oriented dialect of Tcl, a network topology by oeuvre OTcl scripts, and then the principal NS document simulates that anatomy with mere parameters. In ns2 , network animator (NAM) is utilized for the written consider of the network. Ns-2 is the most popular and widely old network simulator for explore create. NAM interface contains mechanism features that quit and endeavor the framework. [18].

Here, we calculated different performance parameter of MANET routing protocol. Protocol included AODV, DSDV, DSR and OLSR.In NS-2 simulation we apply each of MANET protocol in 10 to 50 nodes and analyzed its performance parameter like throughput, average end to end delay (ms) and no of dropped data packet.

\section{PERFORMANCE METRIC}

Throughput: - The throughput is evaluated at which the aggregation packet is delivered successfully from one symptom to other over a network is glorious as throughput. The throughput is usually sounded in bits per gear (bits/sec). A throughput with a higher appreciate is statesman oftentimes a dead prize in every web. Mathematically, throughput can be definite by the following masses instruction below:

$$
\text { Throughput }=\frac{(\text { Quantity of Delivered Packet } * \text { Packet Size })}{\text { Total Simulation Time }}
$$

\section{EXPERIMENTAL WORK}

This research is conducted using separate circumstance network simulation software illustrious as NS-2. In say to tackle the empirical judgment, the most newly purchasable variation, NS-2.35 is one of the most extensively used freely available simulators supported on Unix platform (Fedora 15 in experiment), which incorporates most of the MANET routing parameters. The simulation entities used during the programmed of the network simulation modeling are sweating constellation, salience design, mobility design and nodes. The parameters that get been utilized in the people experiments are summarized in Table 1 as given below

Table 1. Simulation Parameters

\begin{tabular}{|c|c|c|}
\hline $\begin{array}{c}\text { Serial } \\
\text { No. }\end{array}$ & Parameters & Value \\
\hline 1 & Simulator & NS-2.35 \\
\hline 2 & Number of nodes & $10-50$ \\
\hline 3 & Simulation Time & $100 \mathrm{sec}$. \\
\hline
\end{tabular}

\begin{tabular}{|c|c|c|}
\hline 4 & Area & $300 * 300 \mathrm{~m} 2$ \\
\hline 5 & Traffic Source & CBR \\
\hline 6 & Packet Size & 512 Bytes \\
\hline 7 & Mobility model used & $\begin{array}{c}\text { AODV,DSDV,DSR, } \\
\text { OLSR }\end{array}$ \\
\hline 8 & MAC Layer & IEEE 802.11 \\
\hline
\end{tabular}

\section{SIMULATION AND OBSERVATION}

The simulating results are shown in the following graphs below. The action of AODV, DSDV, DSR and OLSR are based on the various numbers of nodes. "Fig. 1" highlights the individual performances of AODV, DSDV, DSR and OLSR protocols for throughput with 10 books of nodes. From figure it is observed that DSDV protocols mortal wagerer show than AODV, DSR and OLSR protocols.

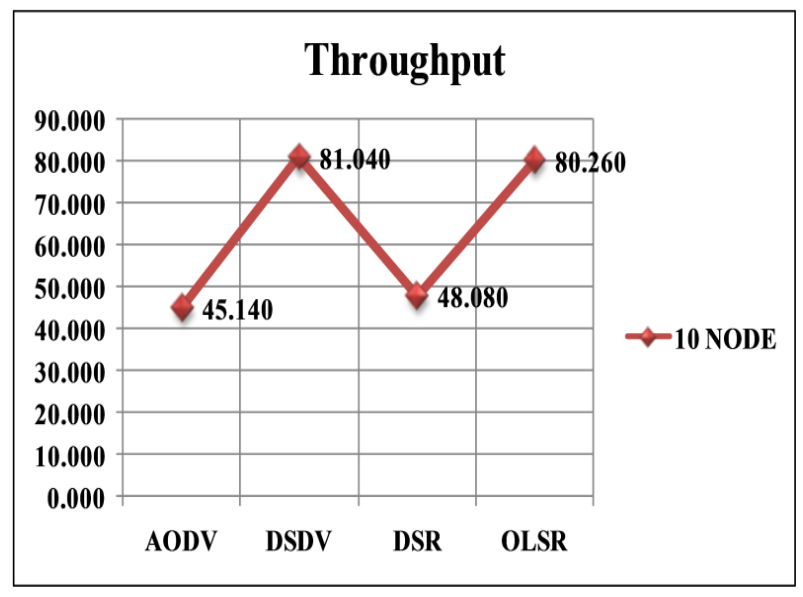

Fig.1: Throughput for 10 Nodes

Fig 2 highlights the relation action of AODV DSDV, DSR and OLSR protocols for throughput with 20 nodes. From graph, it is observed that for elfin classify of nodes up to 20 lottery, the action of DSDV protocol tally exceed performance than AODV, DSR and OLSR protocols.

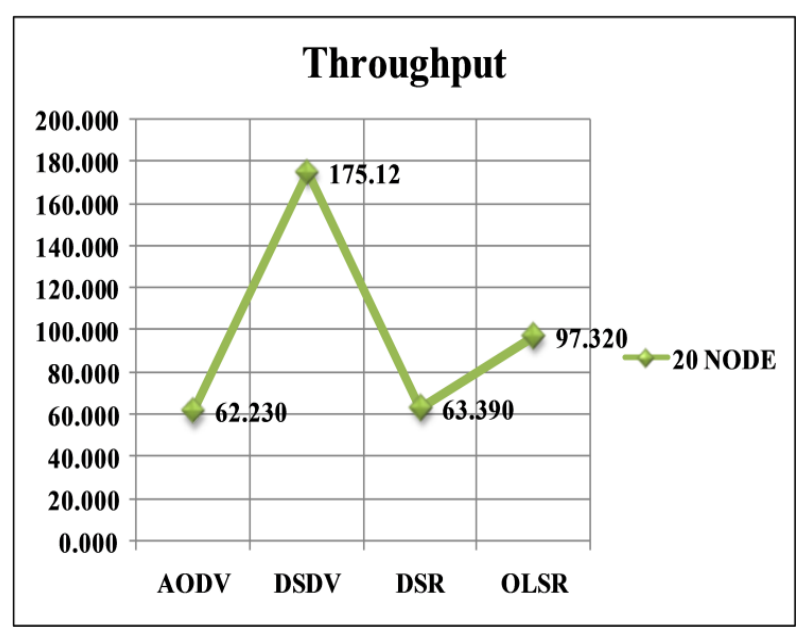

Fig 2: Throughput for 20 Nodes

Fig.3 highlights the congregator execution of AODV, DSDV, OLSR and DSR protocols for complete throughput with 30 
nodes. From personage it is observed that DSDV protocol outperformed among AODV, DSR and OLSR protocols.

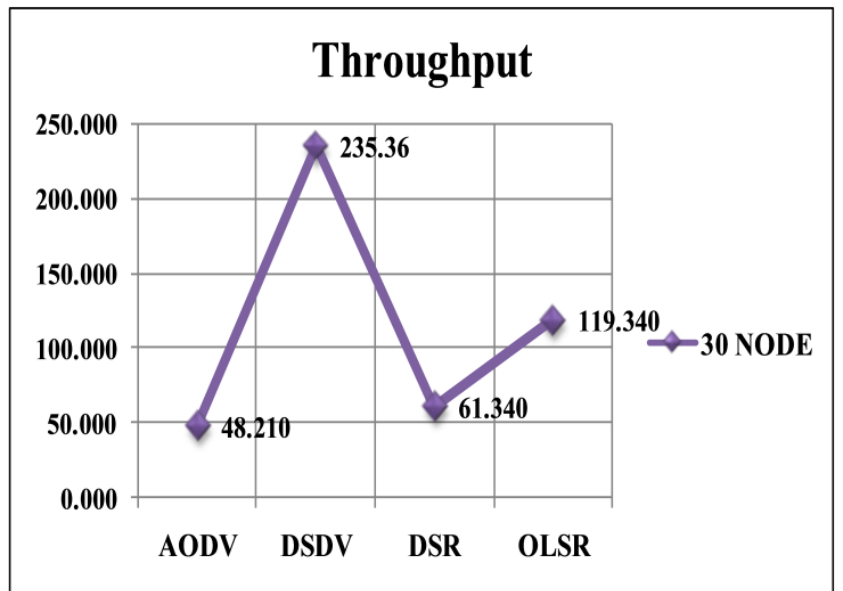

Fig.3: Throughput for 30 Nodes

Fig.4 highlights the relative performance of AODV, DSDV, DSR and OLSR protocols for throughput with 40 nodes. From figure it is observed that DSDV protocol outperformed among AODV, DSR and OLSR protocols.

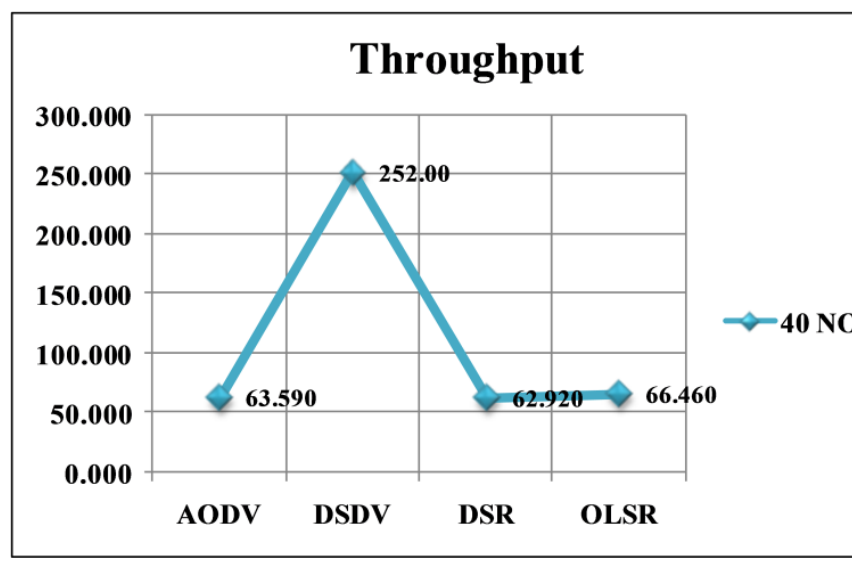

Fig.4: Throughput for 40 Nodes

Fig.5 highlights the congregator execution of AODV, DSDV, OLSR \& DSR protocols for complete throughput with 50 nodes. From illustration it is observed that DSDV rule outperformed among AODV, DSR and OLSR protocols.

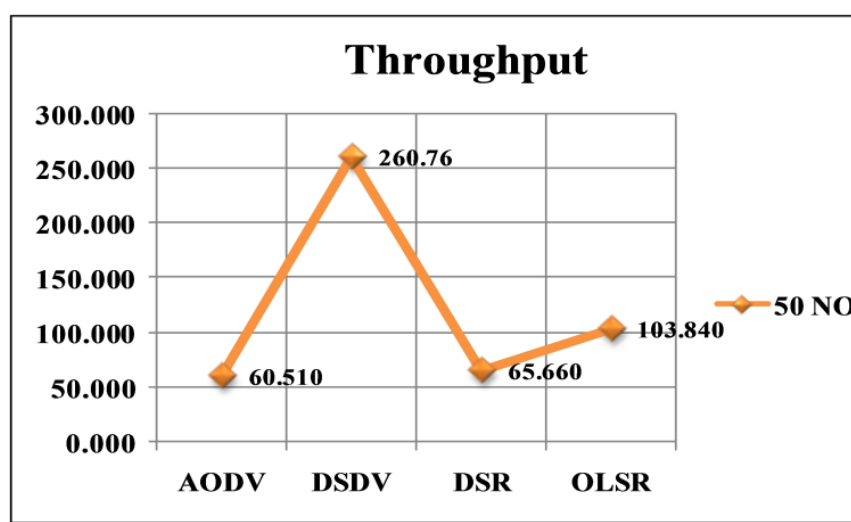

Fig.5: Throughput for 50 Nodes
Fig.6 highlights the congener action of AODV, DSDV, DSR and OLSR protocols for throughput with varied numbers of nodes as $10,20,30,40,50$. From amount it is observed that DSDV protocol individual gambler performance over AODV, DSR and OLSR protocol. It is observed that up to 10 drawing of nodes, DSDV and OLSR protocol hold isochronous action but above 10 numbers of nodes, DSDV is advisable to execution as compared to AODV, DSR and OLSR protocol.

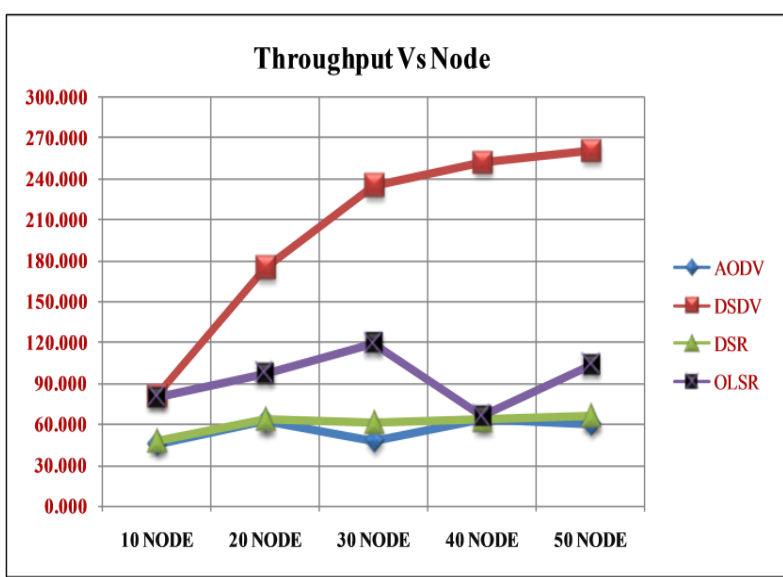

Fig.6: Throughput Vs Number of Nodes

\section{PERFORMANCE COMPARISION}

Varying number of nodes has a major effect on the network parameters. In this scenario, throughput of four MANET protocols calculated by three authors. Table 2 depicts the variation in throughput by increasing number of nodes. On an average throughput increases as network density increases in the networks. Two protocols DSR and AODV analyzed by Gauri M. Patil et.al and it found that throughput increases when nodes size were increases. Results are to be same with respect to DSDV and OLSR on increases nodes density. DSDV has high throughput of $260.76 \mathrm{kbps}$ with 50 nodes.

Table 2. Performance Comparison

\begin{tabular}{|c|c|c|c|c|c|c|}
\hline \multirow[t]{2}{*}{ Protocols } & \multirow[t]{2}{*}{ Author } & \multicolumn{4}{|c|}{ Nodes } & \multirow[b]{2}{*}{50} \\
\hline & & 10 & 20 & 30 & 40 & \\
\hline DSR & $\begin{array}{l}\text { Gouri M. } \\
\text { Patil, et al. }\end{array}$ & 272.90 & 272.80 & 271.91 & - & 272.56 \\
\hline$\overline{\text { AODV }}$ & $\begin{array}{l}\text { Gouri M. } \\
\text { Patil, et al. }\end{array}$ & 282.80 & 282.92 & 283.44 & - & 282.89 \\
\hline DSDV & Bhat A. & 185 & 210 & 250 & 265 & 290 \\
\hline OLSR & $\begin{array}{l}\text { Dabre } \\
\text { U.A. et al. }\end{array}$ & 35.78 & 39.01 & 43.69 & 54.32 & 50.42 \\
\hline AODV & Proposed & 45.140 & 62.230 & 48.210 & 63.590 & 60.510 \\
\hline DSDV & Proposed & 81.040 & 175.12 & 235.36 & 252.00 & 260.76 \\
\hline DSR & Proposed & 48.080 & 63.390 & 61.340 & 62.920 & 65.660 \\
\hline OLSR & Proposed & 80.260 & 97.320 & 119.340 & 66.460 & 103.840 \\
\hline
\end{tabular}

The above table depicts throughput of 10-50 nodes for four MANET routing protocol having simulation time 100 second. In this observation, results were found that throughput of DSDV has better performance with respect to increasing nodes. After observation of the above table, results show that DSDV has better performance and others have fluctuated when increases the nodes in the networks. 


\section{CONCLUSION}

This research was conducted to judge the four MANET protocols i.e. DSR, AODV, OLSR and DSDV supported on CBR interchange. These routing protocols were compared in damage of throughputs when subjected to varying separate of nodes. There are various authors have worked in the field of MANET as mentioned in the literature study. The authors have utilized larger continuance for framework indication, fix interference region, higher grasp for restraint constellation, varying ascertain of nodes (10-50) and successfully shown that the results of DSDV prescript is eminent for throughput for the supposition framework environment, the results of which are reflected in Fig 6. So authors have concurred that the convinced executions metrics are comfortable complex to watch which of them has covered all modify action in MANET. After analysis of this work, it should be implemented on a NS-3 simulator for achieving better results.

\section{REFERENCES}

[1] Ambhaikar, A., Sharma, H.R. and Mohabey, V.K. 2010. Scalability Performance of MANET Routing Protocols with Reference to Variable Pause Time. International Journal on Computer Science and Engineering. 02, 1-5.

[2] Elizabeth, M. Royer, Toh , C. K. 1999. A Review of Current Routing Protocols for Ad Hoc Mobile Wireless Networks. 46-55.

[3] Parekh, V., and Wandra, K. H. 2013. Effects of Traffic Load and Mobility on AODV, DSR and DSDV Routing Protocols in MANET. 3(1), 467-472.

[4] Garousi, V. 2001. Simulating Network traffic in Multihop Wireless Ad Hoc Networks based on DSDV (Destination Sequenced Distance Vector) protocol using NS (Network Simulator) Package, University of Waterloo, Fall.

[5] Das, S. R., and Perkins, C.E. and Royer, E.M. 2000. Performance Comparison of Two on Demand Routing Protocols for Ad Hoc Networks. IEEE INFOCOM 2000. Nineteenth Annual Joint Conference of the IEEE Computer and Communications Societies, 3, 3-20.

[6] Chao, Chih-Min, Sheu, Jang-Ping, and Cheng Ta Hu. 2003. Energy- Conserving Grid Routing Protocol in Mobile Ad Hoc Networks. IEEE Proceedings of the 2003 International Conference on Parallel Processing (ICPP'03).

[7] Zamam, R. U. 2016. An Efficient DSDV Routing Protocol for Wireless Mobile Ad Hoc Networks and its Performance Comparison. http://www.computer.org/ portal.
[8] Perkins, C.E. and Bhagwat, P. 1994. Highly Dynamic Destination Sequence-Vector Routing (DSDV) for Mobile Computers. Computer Communication Review, 24(4), 234-245.

[9] Rahman, A., Islam, A., and Talevski, A. 2009. Performance Measurement of Various Routing Protocols in Ad-hoc Network. International Multi Conference of Engineers and Computer Scientists, March 18 - 20.

[10] Khan, K. U., Zaman, R. U., and Reddy, A. V. 2008 Performance Comparison of On-Demand and Table Driven Ad Hoc Routing Protocols using NCTUns . Tenth International Conference on Computer Modeling and Simulation.

[11] Arun Kumar, Reddy Loknath, Hiremath, P. S. 2008. Performance Comparison of Wireless Mobile Ad-Hoc Network Routing Protocols. IJCSNS International Journal of Computer Science and Network Security,8, 36.

[12] Gowrishankar, S. , Basavaraju, T.G. , Singh, M. Subir Kumar Sarkar, S. K. 2010. Scenario based Performance Analysis of AODV and OLSR in Mobile Ad Hoc Networks. Proceedings of the 24th South East Asia Regional Computer Conference, November 18-19.

[13] Setty, S.P. 2010. Performance Evolution of AODV in Different Environment. International Journal of Engineering Science and Technology. 2(7), 2976-2981.

[14] Vetrivelan, N., Reddy, A. V. 2008. Performance Analysis of Three Routing Protocols for Varying MANET Size. Proceeding of the International Multi Conference of Engineers and Computer Scientists. 2,3-8.

[15] Mahmoud, Ali El-Haj, Khalaf, R. and Kayssi. 2007. Performance of the AODV and DSDV Routing Protocols in Mobile Ad-Hoc Networks, Lebanon.

[16] Jorg, David Oliver. 2003. Performance Comparison of MANET Routing Protocols in Different Network Sizes. Computer Networks \& Distributed Systems.

[17] Broch, J. , Maltz, D. A. , Johnson, D. B. , Hu, Y. C. and Jetcheva, J. 1998. A Performance Comparison of MultiHop Wireless Network Routing Protocols. Proceedings of the Fourth Annual ACM/IEEE International Conference on Mobile Computing and Networking October 25-30, Dallas,Texas,USA,3-25.

[18] Rajan, C., Geetha, K., Rasi, C., Priya, Geetha, S., and Manikandan 2015. A Simple Analysis on Novel Based Open Source Network Simulation Tools for Mobile Ad Hoc Networks. 5, 2-3. 